Cite this: Food Funct., 2014, 5, 375

\title{
Pasta supplemented with isolated lupin protein fractions reduces body weight gain and food intake of rats and decreases plasma glucose concentration upon glucose overload trial
}

\author{
Jessica Capraro, ${ }^{\text {*a }}$ Chiara Magni, ${ }^{a}$ Alessio Scarafoni, ${ }^{a}$ Rosita Caramanico, ${ }^{\text {ab }}$ \\ Filippo Rossi, ${ }^{c}$ Mauro Morlacchini ${ }^{\mathrm{d}}$ and Marcello Duranti ${ }^{\mathrm{a}}$
}

\begin{abstract}
The supplementation of foods with biologically active compounds can be a powerful approach for improving diet and well being. In this study we separately included in pasta matrices a concentrate of $\gamma$-conglutin, a glucose-lowering protein from Lupinus albus seeds, an isolate of the other main lupin storage proteins and ovalbumin, at a ratio corresponding to $125 \mathrm{mg}$ of pure protein in $100 \mathrm{~g}$ of pasta. With these products we fed rats made hyperglycaemic, for 3 weeks. Among the most relevant changes measured in body and blood parameters were: (i) a significant reduction in food intake of rats fed $\gamma$-conglutin concentrate supplemented pasta and a significant limitation in the body weight increase in rats fed $\alpha, \beta$ and $\delta$-conglutin isolate supplemented pasta, while the food conversion indices were unchanged; (ii) a reduction in glycaemia upon glucose overload trial, especially in the $\gamma$-conglutin concentrate supplemented pasta fed animals, at a dose of $45 \mathrm{mg}$ per $\mathrm{kg}$ body weight. The correlations among the measured parameters are discussed. Overall, the results evidence the potentiality of supplementing traditional foods with exogenous nutraceutical seed proteins to control body weight gain and glycaemia.
\end{abstract}

Received 11th November 2013 Accepted 23rd November 2013

DOI: $10.1039 /$ c3fo60583c

www.rsc.org/foodfunction their increasing incidence and prevalence throughout the world. ${ }^{1}$ In this respect, the kinetics of glucose release and absorption after food ingestion and the resulting effects on the synthesis of and sensitivity to insulin, as well as the regulation of satiety, are gaining interest for the prevention of diabetes and obesity.

Lupin seeds and flours are among the natural foods which have been claimed to have anti-diabetic properties by traditional medicine. As a matter of fact, the active principle responsible for the glucose-lowering activity has unequivocally been identified as the protein $\gamma$-conglutin that, in Lupinus albus seeds constitutes about $5 \%$ of total seed proteins, corresponding to about $2 \mathrm{~g}$ of $\gamma$-conglutin in $100 \mathrm{~g}$ of dry seeds or flour. Significant variations in the $\gamma$-conglutin content amongst $L$. albus varieties have not been reported so far. Not only has this lupin protein repeatedly been shown to decrease glycaemia in animals and humans, ${ }^{2,3}$ but its interaction with the putative target cells, including myocytes and hepatocytes, ${ }^{4,5}$ proved to produce a number of effects which have collectively been classified as insulin-mimetic activities. Despite this potentiality, no study on the effects of $\gamma$-conglutin incorporated into a food matrix has been undertaken so far.

Pasta is a traditional food which, for many structural and technological reasons, can be considered an effective vehicle for bioactive proteins and peptides. Consequently, we have prepared pasta samples supplemented with a $\gamma$-conglutin 
concentrate or the isolate of remnant main lupin seed proteins as well as with ovalbumin, as a control. With these samples, we have fed rats for three weeks and measured various body and blood parameters.

Thus, the objective of this work was to compare the effects of a diet based on pasta containing small amounts of specific lupin protein fractions on some physiological and biochemical parameters.

\section{Material and methods}

\subsection{Materials}

White lupin seeds (Lupinus albus, var. Multitalia) were a kind gift from Agroservice S.p.A., Rocchetta, San Severino Marche, Italy.

Ovalbumin was purchased from Sigma Aldrich (Milan, Italy). Chemicals were all reagent grade by Sigma Aldrich (Milan, Italy), unless specified otherwise.

\subsection{Lupin protein fractionation}

Mature dry seeds of Lupinus albus, L. were used as a source of the protein fractions. Lupin proteins were fractionated as described by Sironi with some minor modifications. ${ }^{6}$ Briefly, the seeds were milled to flour which was sieved through an 80 mesh sieve. The proteins in the flour were extracted with distilled water containing $0.5 \mathrm{M} \mathrm{NaCl}$ in the ratio $1 / 10 \mathrm{w} / \mathrm{v}$ at $4{ }^{\circ} \mathrm{C}$ for 3 hours. The $\mathrm{pH}$ was constantly kept between 7.0 and 9.0 by the addition of $0.1 \mathrm{M} \mathrm{NaOH}$. The slurry was centrifuged at $10000 \times$ $g$ at $4{ }^{\circ} \mathrm{C}$ for $30 \mathrm{~min}$. The supernatant was adjusted to $\mathrm{pH} 4.5-5.5$ with acetic acid for protein isoelectric precipitation. The resulting suspension was centrifuged as above. The pellet was washed twice with distilled water at $\mathrm{pH}$ around 5.0. The washed pellet was then freeze dried. This fraction consisted of the isoelectrically precipitated main lupin proteins. The fraction soluble at pH 5.0 was adjusted to $\mathrm{pH} 7.0$ with $0.1 \mathrm{M} \mathrm{NaOH}$ and $20 \mathrm{mM} \mathrm{ZnCl}{ }_{2}$ was added. The resulting suspension was centrifuged as above and the pellet recovered. The pellet was washed twice with distilled water and freeze dried. As it will be seen below, this fraction mainly consisted of $\gamma$-conglutin.

\subsection{SDS-PAGE of the protein fractions}

The protein samples were suspended in the sample buffer in the ratio $1: 20(\mathrm{w} / \mathrm{v})$. The sample buffer consisted of $0.25 \mathrm{M}$ Tris$\mathrm{HCl}$, pH 6.8, $7.5 \mathrm{~mL}$ per $100 \mathrm{~mL}$ glycerol, $20 \mathrm{mg} \mathrm{mL}^{-1} \mathrm{SDS}$ and $2.5 \mathrm{~mL}$ per $100 \mathrm{~mL}$ 2-mercaptoethanol. After heating at $100{ }^{\circ} \mathrm{C}$ for $5 \mathrm{~min}$, each sample was loaded on the gel. SDS-PAGE was carried out on $7 \times 8 \mathrm{~cm} 12 \%$ polyacrylamide gels, using a miniProtean III cell (Bio-Rad). The gels were stained with Coomassie blue. $^{7}$ The gels were digitalised in an Epson Perfection V500 Scanner and analysed with ImageMaster 1-D Elite Software (GE Healthcare, Milan, Italy).

\subsection{Western blotting}

The proteins in gels were transferred to $0.45 \mu$-pore nitrocellulose membranes (Protran, 110 Whatman, Dassel, Germany) by using the TE 77 PWR Semidry Transfer Unit (Amersham
Biosciences), according to Towbin, Staehelin and Gordon. ${ }^{8}$ $\gamma$-Conglutin was immune-detected as already described by Magni. ${ }^{9}$

\subsection{Pasta preparation and protein inclusion}

Pasta supplied to the animals was a mix of commercial dry pasta and dry test pasta, including selected protein fractions from lupin seeds and ovalbumin, as the control. Test pasta containing $\gamma$-conglutin concentrate was mixed with commercial pasta in a $1 / 4$ ratio $(\mathrm{w} / \mathrm{w}) ; \alpha+\beta+\delta$-conglutin isolate and ovalbumin containing pasta were mixed with commercial pasta in a $1 / 8$ ratio $(\mathrm{w} / \mathrm{w})$. All pasta samples were uncooked to allow easy grinding to a fine powder.

Test pasta was prepared according to standard protocols. Durum wheat semolina of good pasta-making performance (protein: $14.3 \mathrm{~g}$ per $100 \mathrm{~g}$ d.w.; dried gluten: $13.2 \mathrm{~g}$ per $100 \mathrm{~g}$ ) was supplied by Molino Grassi (Parma, Italy). Semolina and protein fractions $(1 \mathrm{~g}$ per $100 \mathrm{~g}$ semolina and $1 \mathrm{~g}$ per $100 \mathrm{~g}$ each of the lupin protein fraction and commercial ovalbumin) were mixed with water (kept at $40{ }^{\circ} \mathrm{C}$ ) to produce a mixture with a final moisture content of $34 \%$. After mixing for 10 minutes, each blend was extruded and formed into a macaroni shape $(7 \mathrm{~mm}$ external diameter) using a continuous pilot-scale plant $(20 \mathrm{~kg}$ $\mathrm{h}^{-1}$; MAC 30, Italpast, Parma, Italy). Fresh pasta was finally dried in a pilot-scale drier (50 $\mathrm{kg} \mathrm{h}^{-1}$, Braibanti, Milan, Italy) using a low-temperature drying cycle $\left(50{ }^{\circ} \mathrm{C} \max\right.$. for $14 \mathrm{~h}$ ), according to Marti, Seetharaman and Pagani. ${ }^{10}$

\subsection{Animal care and diets}

Forty eight male Sprague Dawley rats weighing $195.7 \pm 13.5 \mathrm{~g}$ were adapted to a standard diet, consisting of commercial pasta $(80.5 \%)$, casein $(10 \%)$, Arbocel $(4 \%)$, minerals $(3.5 \%)$, olive oil $(1 \%)$ and vitamins $(1 \%)$ for seven days. Tap water containing $10 \%$ glucose was supplied ad libitum to the animals during the adaptation phase, in order to induce a hyperglycemic state and also during the subsequent three week experimental period with test pasta.

Between the adaptation phase and the test period, glucose administration was suspended for 12 hours and the glucose plasma levels were measured.

All procedures involving rats and their care were performed according to the Italian Law on animal tests (D.L. 116/1992).

2.6.1 Chronic treatment with test pasta. The test diet consisted of the above mentioned diet (adaptation diet) with the substitution of part of the commercial pasta with a corresponding amount of test pasta samples. The animals (24) were divided into 3 homogenous groups, according to their blood glucose concentration. The animals were fed ad libitum with a diet containing pasta supplemented with lupin $\gamma$-conglutin concentrate, $\alpha+\beta+\delta$-conglutin isolate and ovalbumin, respectively, for three weeks. Glucose containing water was freely available. Every day the food intake and the body weight of each animal were measured. At the end of the experimental period, the animals were fasted for 12 hours, sacrificed, and the blood was collected for the determination of glycaemia, insulin and other hormone concentrations. 
2.6.2 Acute treatment with test pasta (glucose overload trial). At the end of the adaptation period, 24 untreated animals were divided into 3 homogenous groups, according to their blood glucose concentration. The animals were fasted for 20 hours. Then, $10 \mathrm{~g}$ of $\gamma$-conglutin, $\alpha+\beta+\delta$-conglutins and ovalbumin supplemented pasta samples were supplied to the animals, which they ate entirely within 30 minutes. Immediately after this meal, $2 \mathrm{~g} \mathrm{~kg}^{-1}$ of D-glucose was administered to the animals by gavage. Before the meal and 30-60-90-120 minutes after glucose administration, blood glucose was determined.

\subsection{Blood analysis}

Glucose concentrations were measured using a kit, based on an enzymatic method of detection, purchased from R-Biopharm (Germany). Insulin, leptin and total ghrelin were assayed using ELISA commercial kits from Millipore Corporation (USA) and the microplate reader 3550 (BioRad, Milan, Italy).

\subsection{Statistical analysis}

The data obtained were analyzed by the SAS statistics program (SAS Inst., Cary, NC, USA) version 9.2, using the procedure of G.L.M. (General Linear Model) of the software and adopting the following experimental model:

$$
y=\mu+\alpha+\varepsilon
$$

where: $y=$ parameters (blood glucose, daily weight gain, food intake, etc.); $\mu=$ population means; $\alpha=$ effect of protein type ( $\gamma$-conglutin, $\alpha+\beta+\delta$-conglutins, ovalbumin); $\varepsilon=$ experimental error.

Analysis of variance was carried out on the data collected by using the above cited software.

The Bonferroni test was used to compare the means. The differences were considered significant at $P<0.05$. The relationships between variables were determined by means of Pearson's correlation coefficient, using the software PROC CORR of SAS 9.2.

\section{Results}

\subsection{Electrophoretic analysis of the protein fractions included in the pasta samples}

The two isolated lupin protein fractions and ovalbumin, which were included in the test pasta dough at a dose of $1 \mathrm{~g}$ per $100 \mathrm{~g}$, were submitted to SDS-PAGE under reducing conditions and the resulting profiles are shown in Fig. 1. By comparing the electrophoretic patterns with the $\gamma$-conglutin and total protein extract references and on the basis of previous separations and mass spectrometry analysis, ${ }^{11}$ it was concluded that the lane $\mathrm{B}$ of Fig. 1 contained primarily $\gamma$-conglutin, while the lane A consisted of the other main lupin cotyledonary proteins, that is $\alpha+\beta+\delta$-conglutins, which, having an acidic $\mathrm{p}$, precipitated at $\mathrm{pH}$ 4.5-5.0 (see details under Methods, paragraph 2.2). These latter proteins consisted mainly of 11S- (legumin-like), 7S- (vicilinlike) and 2S-globulins, respectively. For a molecular

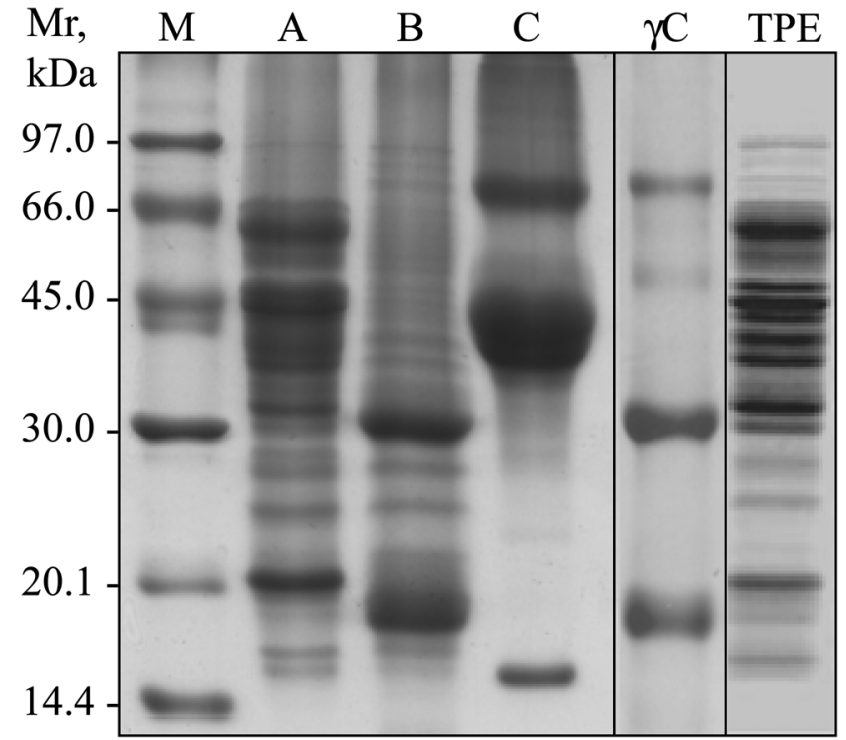

Fig. 1 SDS-PAGE under reducing conditions of the protein fractions added to pasta. Lane A: isoelectric precipitate; lane $\mathrm{B}: \mathrm{Zn}^{2+}$ precipitate (containing primarily $\gamma$-conglutin); lane $\mathrm{C}$ : ovalbumin; lane $\mathrm{M}$ : marker proteins. $\gamma \mathrm{C}: \gamma$-conglutin reference, TPE: total protein extract reference.

characterization of these proteins see the reference Duranti, Consonni, Magni, Sessa, and Scarafoni. ${ }^{12}$

Densitometric analysis of the lane B showed that the polypeptides corresponding to $\gamma$-conglutin, that is the bands of 30 and $17 \mathrm{kDa}$, amounted to about $50 \%$ of the total proteins in the lane. Therefore the actual amount of $\gamma$-conglutin in the test pasta samples was calculated to be $0.5 \mathrm{~g}$ per $100 \mathrm{~g}$. According to this finding and to the ratio $1: 4$ by weight of the mix between test pasta and commercial pasta, the concentration of pure $\gamma$-conglutin in the pasta mix supplied to rats with the diet was $0.125 \mathrm{~g}$ per $100 \mathrm{~g}$, corresponding to the same amounts of $\alpha+\beta+\delta$ conglutins and ovalbumin in the respective test pasta products.

\subsection{Chronic effects of pasta intake on rat growth parameters and basal blood glucose levels}

The effects of the three test pasta products on the rat body parameters measured after the adaptation period and the induction of a hyperglycemic condition are reported in Table 1. Considering the amounts of added proteins in the pasta fed to the animals each day and the average daily intake and body weight, it was calculated that the dosages of supplemented proteins were about $90 \mathrm{mg}$ per $\mathrm{kg}$ per day.

Initial weights of the rats did not differ in the three groups, while differences were marked at the end of the 3 weeks trial: in particular a lower body weight was observed for rats fed the $\alpha, \beta$ and $\delta$-conglutin isolate compared to animals fed the ovalbumin supplemented pasta. The food intake of rats fed $\gamma$-conglutin concentrate supplemented pasta was also remarkably and significantly lower than that observed with rats fed ovalbumin supplemented pasta. 
Table 1 Growth parameters and food intake of rats fed pasta supplemented with lupin $\gamma$-conglutin concentrate, $\alpha+\beta+\delta$-conglutin isolate and ovalbumin for three weeks. For each of the three treatments, a separate set of eight rats was used. Data are presented as means \pm standard deviation $^{a}$

\begin{tabular}{lllll}
\hline Treatment $(n=8)$ & Initial weight $(\mathrm{g})$ & Final weight $(\mathrm{g})$ & ADG $^{*}(\mathrm{~g}$ per day $)$ & Food intake $(\mathrm{g} \text { per day })^{\mathrm{CI}^{\S}}$ \\
\hline$\gamma$-Conglutin concentrate & $192.98 \pm 20.17$ & $345.50 \pm 34.22^{\mathrm{ab}}$ & $5.87 \pm 1.28$ & $18.46 \pm 2.66^{\mathrm{a}}$ \\
$\alpha+\beta+\delta$-Conglutin isolate & $195.03 \pm 10.41$ & $331.83 \pm 11.60^{\mathrm{a}}$ & $5.26 \pm 0.36$ & $18.76 \pm 0.89^{\mathrm{ab}}$ \\
Ovalbumin & $199.02 \pm 8.97$ & $370.20 \pm 10.76^{\mathrm{b}}$ & $6.58 \pm 0.42$ & $21.32 \pm 1.41^{\mathrm{b}}$
\end{tabular}

$a *$ ADG: average daily gain; ${ }^{\S} \mathrm{CI}=$ conversion index (food intake/growth); ${ }^{\mathrm{a}, \mathrm{b}} \mathrm{P}>0.05$ (Bonferroni test).

The constancy of the conversion index (CI) for all samples suggested a similar efficiency of the three groups in converting food to energy.

Table 2 reports the fasting glycaemia levels observed at the beginning and the end of the treatment. Glycaemia measured in rats fed lupin protein supplemented pasta for three weeks did not significantly differ from that measured with ovalbumin.

At the end of the treatment, no statistically significant changes in hormone levels between the lupin protein supplemented pasta and the ovalbumin supplemented pasta fed animals were monitored (Table 2), also due to the great variability.

\subsection{Correlations between the measured parameters}

All the measured parameters have been correlated by using the Pearson correlation coefficient in order to investigate the possible inter-dependences, as described under Methods and shown in Table 3.

After the chronic treatment, blood glucose, food intake, growth and leptin blood level of treated animals correlated positively: higher food intake induced higher growth and glycaemia; leptin is produced by adipose tissue, therefore higher growth induced higher release of leptin. Leptin and insulin also correlated positively, according to Amitani, Asakawa, Haruka, and Inui. ${ }^{13}$ In our experiment both hormones were directly related and this could be due to the positive relationship between insulin and live weight. Since leptin is related to body weight, we could hypothesize that heavier animals have higher concentrations of insulin and leptin. Anyway the positive relationship between insulin and leptin observed in our experiment is a quite common finding. ${ }^{\mathbf{1 4}}$

The interpretation of the positive relationship between ghrelin and leptin is more complex. ${ }^{15}$ Usually the trends of these two hormones are opposite, but they are strongly affected by blood glucose. When glycaemia is high, ghrelin inhibits leptin, while at lower glucose concentrations this does not happen. ${ }^{\mathbf{1 6}}$

\subsection{Glucose overload trial with test pasta samples}

The animals (24) fed the adaptation diet for one week to induce hyperglycemia and fasted for 20 hours were submitted to the glucose overload trial. During the 20 hour fasting, rats were allowed to drink tap water with no glucose added. Then, as detailed under Methods, $10 \mathrm{~g}$ of $\gamma$-conglutin concentrate, $\alpha+\beta+\delta$-conglutin isolate and ovalbumin supplemented pasta samples were given to the animals, which entirely ate them within 30 minutes. Immediately after this meal, blood glucose was determined and $2 \mathrm{~g} \mathrm{~kg}^{-1}$ of D-glucose was administered to the animals by gavage. The amount of administered $\gamma$-conglutin in this experiment corresponded to about $45 \mathrm{mg}$ per $\mathrm{kg}$ body weight. The glycaemia levels every $30 \mathrm{~min}$ for two hours of the glucose overload trial are reported in Table 4. Major changes were observed up to $60 \mathrm{~min}$ from the treatment, with statistically significant lower increments for $\gamma$-conglutin concentrate supplemented pasta. At 90 minutes all plasma glucose levels reached a maximum and then declined at 2 hours, steadily approaching the basal levels.

A global estimation of the glycaemia trend is depicted by the incremental areas under the curve (AUC) of the glucose overload trial, reported in Fig. 2. As it can be seen, the plasma glucose reduction by $\gamma$-conglutin concentrate was apparent already at the first $30 \mathrm{~min}$, though the differences were not statistically significant. Conversely, large and statistically significant differences were visible at $60 \mathrm{~min}$ and up to 90 minutes, where the AUCs induced by the $\gamma$-conglutin concentrate included in pasta were dramatically lower than those obtained with pasta supplemented with ovalbumin. This finding is consistent with the glucose-lowering activity of lupin $\gamma$-conglutin previously measured with the purified protein administered by gavage in

Table 2 The fasting glycaemia and energy metabolism-related hormone levels in rats fed pasta supplemented with lupin $\gamma$-conglutin concentrate, $\alpha+\beta+\delta$-conglutin isolate and ovalbumin for three weeks. For each of the three treatments, a separate set of eight rats was used. Data are presented as means \pm standard deviation ${ }^{a}$

\begin{tabular}{|c|c|c|c|c|c|}
\hline Treatment $(n=8)$ & $\begin{array}{l}\text { Initial glycaemia } \\
\left(\mathrm{mg} \mathrm{dL}^{-1}\right)\end{array}$ & $\begin{array}{l}\text { Final glycaemia } \\
\left(\mathrm{mg} \mathrm{dL}^{-1}\right)\end{array}$ & $\begin{array}{l}\text { Insulin } \\
\left(\mathrm{ng} \mathrm{mL}^{-1}\right)\end{array}$ & $\begin{array}{l}\text { Leptin } \\
\left(\mathrm{ng} \mathrm{mL}^{-1}\right)\end{array}$ & $\begin{array}{l}\text { Ghrelin } \\
\left(\mathrm{ng} \mathrm{mL}^{-1}\right)\end{array}$ \\
\hline$\gamma$-Conglutin concentrate & $132.33 \pm 9.95$ & $131.83 \pm 12.92$ & $0.75 \pm 0.68$ & $1.59 \pm 1.10$ & $0.20 \pm 0.19$ \\
\hline Ovalbumin & $134.00 \pm 6.20$ & $135.17 \pm 17.77$ & $0.86 \pm 0.08$ & $2.14 \pm 1.06$ & $0.21 \pm 0.09$ \\
\hline
\end{tabular}

${ }^{a}$ Bonferroni test: the effect of protein type did not result significant for any analyzed parameters $(P>0.05)$. 
Table 3 Correlation ( $r$, Pearson's coefficient) between blood and growth parameters ${ }^{a}$

\begin{tabular}{|c|c|c|c|c|c|c|c|c|}
\hline & Glycaemia & Insulin & Ghrelin & Leptin & Weight & Intake & CI & $\mathrm{ADG}$ \\
\hline Glycaemia & . & $0.393^{\dagger}$ & NS & $0.452^{*}$ & $0.521 * *$ & $0.540 * *$ & NS & $0.463^{*}$ \\
\hline Insulin & & $\cdot$ & $0.424^{*}$ & $0.625^{*}$ & $0.462^{*}$ & NS & $-0.500^{*}$ & $0.405^{*}$ \\
\hline Ghrelin & & & $\cdot$ & $0.437^{*}$ & NS & NS & NS & NS \\
\hline Leptin & & & & $\cdot$ & $0.706 * *$ & $0.567 * *$ & $-0.582^{* *}$ & $0.649 * *$ \\
\hline Weight & & & & & . & $0.937^{* *}$ & $-0.752^{* *}$ & $0.955^{* *}$ \\
\hline Intake & & & & & & . & $-0.606^{* *}$ & $0.907 * *$ \\
\hline CI & & & & & & & $\cdot$ & $-0.861^{* *}$ \\
\hline ADG & & & & & & & & $\cdot$ \\
\hline
\end{tabular}

rats. ${ }^{5}$ However, in the present work the protein was supplemented into a traditional food.

\section{Discussion}

In this work, the chronic and acute effects of lupin protein fractions physically entrapped into a common food matrix on selected body parameters and plasma glucose levels of rats were studied. Fasting blood glucose levels were in the same range as reported by previous works focusing on glycemic response to diets with different glycemic index or supplemented with $\gamma$-conglutin.,17 An unforeseen finding of this work was the remarkable reduction in food intake and body weight increase induced by pasta supplemented with the lupin protein fractions with respect to the ovalbumin control. Regardless of the hypoglycaemic activity, that is a peculiar property of $\gamma$-conglutin, ${ }^{2,3}$ all lupin proteins showed a relevant effect on satiety and weight gain, although the mechanism of action is far from being understood. Although this result is somehow consistent with a former report by Lee et al.,$^{18}$ who monitored higher satiety and lower energy intake in human subjects fed with lupin enriched bread, the experimental plans of the two works strongly differed, beside being conducted on human subjects and rats. In particular, while these authors included lupin kernel flour in bread, thus providing also lupin fibers, of which the satiating role had already been assessed, ${ }^{19}$ in our case only purified proteins and at very low dosages were used as supplements. Therefore, although a synergic effect between proteins and fibers could reasonably be expected, in our work the observed differences can be attributed to the protein fraction, only.

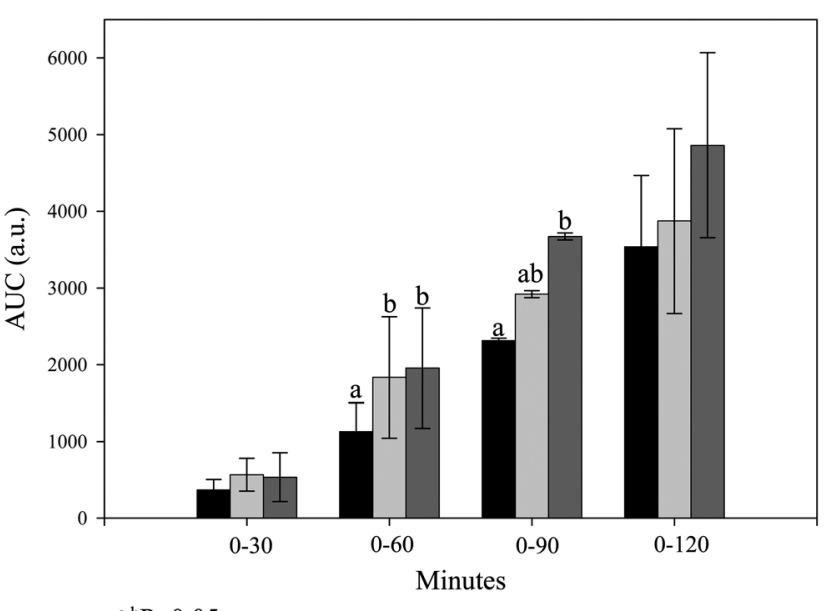

${ }^{\mathrm{a}, \mathrm{b}} \mathrm{P}>0.05$

Fig. 2 Incremental areas under the curve (AUC) of the glucose overload trial. Plasma glucose variations upon administration of pasta supplemented with lupin $\gamma$-conglutin concentrate (black bars), $\alpha^{-}, \beta-$ and $\delta$-conglutin isolate (light grey bars) and ovalbumin (grey bars) to eight animals for each group. Values are expressed as arbitrary units (a.u.). ${ }^{a, b} P>0.05$ (Bonferroni test).

The further notable finding of this work concerned the lowering of the acute glycaemic curve, especially at early times from the initial glucose load, and AUCs specifically induced by $\gamma$-conglutin concentrate supplemented pasta. This result confirms previous findings obtained with pure ${ }^{2,5}$ and raw $^{3}$ $\gamma$-conglutin, thus substantiating its role as a plasma glucosecontrolling natural agent. However, in the present work the biologically active protein has become a component of a food

Table 4 Glycaemia variations upon glucose overload in hyperglycemic rats fed $10 \mathrm{~g}$ pasta supplemented with lupin $\gamma$-conglutin concentrate, $\alpha+\beta+\delta$-conglutin isolate and ovalbumin. For each of the three treatments, a separate set of eight rats was used. Data are expressed as means \pm standard deviation ${ }^{a}$

Glycaemia $\left(\mathrm{mg} \mathrm{dL}^{-1}\right)$ after glucose overload

\begin{tabular}{|c|c|c|c|c|c|}
\hline Treatment $(n=8)$ & Initial glycaemia $\left(\mathrm{mg} \mathrm{dL}^{-1}\right)$ & 30 minutes & 60 minutes & 90 minutes & 120 minutes \\
\hline$\gamma$-Conglutin concentrate & $134.13 \pm 21.60$ & $158.75 \pm 26.28$ & $157.63 \pm 12.32^{\mathrm{a}}$ & $187.63 \pm 32.83$ & $154.50 \pm 22.46$ \\
\hline$\alpha+\beta+\delta$-Conglutin isolate & $145.00 \pm 25.86$ & $182.75 \pm 34.89$ & $178.25 \pm 20.36^{\mathrm{a}, \mathrm{b}}$ & $192.13 \pm 40.39$ & $155.00 \pm 13.77$ \\
\hline Ovalbumin & $137.63 \pm 17.91$ & $173.25 \pm 30.79$ & $196.75 \pm 35.16^{\mathrm{b}}$ & $192.13 \pm 47.30$ & $158.50 \pm 16.90$ \\
\hline
\end{tabular}

${ }^{a}$ a,b $P>0.05$ (Bonferroni test). 
matrix, while in the previous works it was administered by gavage. Other teams have evidenced glycaemia-reducing effects of lupin flours in type II diabetic patients; ${ }^{20}$ however, the authors admitted that their findings could have been affected by the lower carbohydrate content in the lupin meal with respect to the control. Still, pieces of evidence on the specific role played by lupin flours and its components in controlling plasma glucose concentrations are accumulating in the literature. $^{21,22}$

The long term effect on glycaemia was less evident as compared to a previous work, ${ }^{5}$ likely because $\gamma$-conglutin intake through the meal was less controlled in this than in that work, where the protein was administered daily by gavage.

To the best of our knowledge, this work represents the first report on the effects of a biologically active protein included in a food matrix. Indeed food processes (mechanical forces, high temperatures, pressures, etc.) could influence protein intrinsic properties and affect the interactions with other food components. However, it appears from our results that the physical entrapment of $\gamma$-conglutin in the pasta matrix has not hampered its biological activity. It can be argued that the resulting diminished accessibility of the lupin protein to gastric enzymes and extreme low $\mathrm{pH}$ may have preserved the $\gamma$-conglutin covalent structure and allowed its transit into duodenum in an intact and active form. As a matter of facts, $\gamma$-conglutin was shown to be fully resistant to digestive enzymes with optimum $\mathrm{pH}$ at neutral values. ${ }^{23}$ In the present study, the heating effect on protein bio-activity could not be evaluated since pasta was administered to the animals without cooking. However, the presence of intact $\gamma$-conglutin in brine-cooked seeds has been detected (Capraro, unpublished results), although the protein showed decreased solubility, probably due to interactions with other lupin proteins.

This work showed the feasibility of supplementing a traditional food with selected bioactive proteins, whose activities are not influenced by the inclusion. It can be stated that even low amounts of lupin proteins had unforeseen effects on body weight gain, satiety and glycaemia. These findings open new perspectives for the exploitation of lupin $\gamma$-conglutin for the prevention and accompanying therapies of the many glucoserelated diseases and, more in general, of the lupin proteins in weight controlling dietary programs.

\section{Abbreviations}

$\begin{array}{ll}\text { ADG } & \text { Average daily gain } \\ \text { AUC } & \text { Area under the curve } \\ \text { CI } & \text { Conversion index } \\ \text { d.w. } & \text { Dry weight. }\end{array}$

\section{Acknowledgements}

The authors thank Dr Antonio Gallo for his critical revision of the statistical analysis. Jessica Capraro was supported by the grant "Dote Ricerca" of Regione Lombardia and European Social Fund.

\section{References}

1 P. W. Sullivan, E. H. Morrato, V. Ghushchyan and H. R. Wyatt, Diabetes Care, 2005, 28, 1599-1603.

2 C. Magni, F. Sessa, E. Accardo, M. Vanoni, P. Morazzoni, A. Scarafoni and M. Duranti, J. Nutr. Biochem., 2004, 15, 646. 3 J. C. Bertoglio, M. A. Calvo, J. L. Hancke, R. A. Burgos, A. Riva, P. Morazzoni, C. Ponzone, C. Magni and M. Duranti, Fitoterapia, 2011, 82, 933-938.

4 I. Terruzzi, P. Senesi, C. Magni, A. Montesano, A. Scarafoni, L. Luzi and M. Duranti, Nutr., Metab. Cardiovasc. Dis., 2011, 21, 197-205.

5 M. R. Lovati, C. Manzoni, S. Castiglioni, A. Parolari, C. Magni and M. Duranti, Br. J. Nutr., 2012, 107, 67-73.

6 E. Sironi, F. Sessa and M. Duranti, Eur. Food Res. Technol., 2005, 221, 145-150.

7 C. M. Wilson, Methods Enzymol., 1983, 91, 236-247.

8 H. Towbin, T. Staehelin and J. Gordon, Proc. Natl. Acad. Sci. U. S. A., 1979, 76, 4350-4354.

9 C. Magni, C. Ballabio, P. Restani, E. Sironi, A. Scarafoni, C. Poiesi and M. Duranti, J. Agric. Food Chem., 2005, 53, 2275-2281.

10 A. Marti, K. Seetharaman and M. A. Pagani, J. Food Qual., 2013, 36, 133-138.

11 C. Magni, A. Scarafoni, A. Herndl, F. Sessa, B. Prinsi, L. Espen and M. Duranti, Phytochemistry, 2007, 68, 997-1007.

12 M. Duranti, A. Consonni, C. Magni, F. Sessa and A. Scarafoni, Trends Food Sci. Technol., 2008, 19, 624-633.

13 M. Amitani, A. Asakawa, A. Haruka and A. Inui, Front. Neurosci., 2013, 51, 1-12.

14 M. Tsai, A. Asakawa, H. Amitani and A. Inui, Indian J. Endocrinol. Metab., 2012, 16, S543-S548.

15 G. S. Barsh and M. W. Schwartz, Nat. Rev. Genet., 2002, 3, 589-600.

16 E. Otto-Buczkovska and A. Chabot, Postepy Hig. Med. Dosw., 2012, 6, 795-798.

17 M. Kabir, W. R. Salwa, M. Champ, J. Luo, J. Boillot, F. Bruzzo and G. Slama, J. Nutr., 1998, 28, 35-43.

18 Y. P. Lee, T. A. Mori, S. Sipsas, A. Barden, I. B. Puddey, V. Burke, R. S. Hall and J. M. Hodgson, Am. J. Clin. Nutr., 2006, 84, 975.

19 B. J. Archer, S. K. Johnson, H. M. Devereux and A. L. Baxter, Br. J. Nutr., 2004, 91, 591-599.

20 E. R. Dove, T. A. Mori, G. T. Chew, A. E. Barden, R. J. Woodman, I. B. Puddey, S. Sipsas and J. M. Hodgson, Br. J. Nutr., 2011, 106, 1045-1051.

21 M. Fornasini, J. Castro, E. Villacrés, L. Narváez, M. P. Villamar and M. E. Baldeón, Nutr. Hosp., 2012, 27, 425-433.

22 M. E. Baldeón, J. Castro, E. Villacrés, L. Narváez and M. Fornasini, Nutr. Hosp., 2012, 27, 1261-1266.

23 J. Capraro, C. Magni, A. Scarafoni and M. Duranti, J. Agric. Food Chem., 2009, 57, 8612-8616. 